\title{
SWEDEGENE-a Swedish nation-wide DNA sample collection for pharmacogenomic studies of serious adverse drug reactions
}

\author{
Pär Hallberg ${ }^{1}$ - Qun-Ying Yue ${ }^{2} \cdot$ Erik Eliasson $^{3} \cdot$ Håkan Melhus $^{1} \cdot$ Joel Ås $^{1} \cdot$ Mia Wadelius $\mathbb{D}^{1}$
}

Received: 9 November 2019 / Revised: 19 December 2019 / Accepted: 7 January 2020 / Published online: 17 January 2020

(c) The Author(s) 2020. This article is published with open access

\begin{abstract}
SWEDEGENE is a Swedish nation-wide sample collection established to facilitate studies of clinical and genetic risk factors for adverse drug reactions (ADRs). Most cases are recruited among patients reported to the ADR registry at the Swedish Medical Products Agency by health-care professionals. Clinical data are collected both from medical and laboratory records and through interviews using standardized questionnaires. Genome-wide scans and whole-genome sequencing are done, and association studies are conducted using mainly controls from the Swedish TwinGene biobank with data on diagnoses and prescribed drugs. SWEDEGENE was established in 2008 and currently contains DNA and information from about 2550 adults who have experienced specific ADRs, and from 580 drug exposed controls. Results from genome-wide association studies have now been published, and data from whole-genome sequencing are being analyzed. SWEDEGENE has the potential to offer a new means of developing individualized and safe drug therapy through patient pre-treatment screening.
\end{abstract}

\section{Introduction}

Adverse drug reactions (ADRs) are a significant cause of morbidity and mortality, leading not only to individual treatment failures but also to substantially increased healthcare costs. ADRs have been estimated to cause or contribute to at least $5-7 \%$ of hospital admissions [1-4], and to about $3 \%$ of all fatalities [5]. About $10 \%$ of the Swedish healthcare budget has been attributed to ADRs [6].

Virtually all drugs are unsafe in a subset of patients even when used according to the approved label. There is good reason to believe that a significant part of an individual's risk of being intolerant to a drug is explained by genetic predisposition [7]. In some cases, dose-dependent ADRs are known to be caused by mutations in genes involved in the metabolism of the drug or in the drug target. An example is

Pär Hallberg

par.hallberg@medsci.uu.se

1 Department of Medical Sciences, Clinical Pharmacology and Science for Life Laboratory, Uppsala University, Uppsala, Sweden

2 WHO Uppsala Monitoring Center, Uppsala, Sweden

3 Karolinska Institutet, Department of Laboratory Medicine, Clinical Pharmacology, Karolinska University Hospital,

Stockholm, Sweden the dose-dependent bone-marrow suppression that develops in patients with defective detoxification of thiopurines related to genetic variants of the key enzyme thiopurine methyltransferase [8].

Other types of serious ADRs appear to be less dependent on dose. These ADRs - so called idiosyncratic or type B reactions-can affect various organ tissues, including e.g., the heart, liver, skin, kidney, and muscle or cause generalized hypersensitivity reactions [9]. In this category of ADRs, the cause is generally unknown and there are no obvious candidate genes. Microarray-based genotyping of multiple genetic variants as well as next-generation sequencing (NGS), where rarer sequence variants can be discovered, have made it possible to perform genome-wide association studies (GWAS) of these reactions, as well as other types of association analyses. For both of these methods, large numbers of patients are usually needed due to the statistical requirement of correction for multiple testing and for replication of findings.

In the relatively few large-scale genome-wide studies performed on serious ADRs so far, immune-related genetic variants involving the human leukocyte antigen (HLA) molecules in the major histocompatibility complex (MHC) on chromosome 6 have often been implicated as risk factors [10]. Such risk factors have been shown to be drug-specific and to vary between different ethnic populations. A wellknown example is the association between HLA-B*57:01 
and the abacavir-induced hypersensitivity syndrome [11]. Abacavir, a nucleoside reverse transcriptase inhibitor used in the treatment of human immunodeficiency virus (HIV), is associated with hypersensitivity reactions in $5-8 \%$ of patients [12]. Introduction of HLA-B*57:01 screening prior to abacavir therapy has reduced the incidence of this ADR from up to 8 to $<1 \%$ [13].

In the current project, we are collecting ADRs on a large scale in Sweden. We aim to establish a large nation-wide DNA sample collection with clinical data to enable studies of both genetic and clinical risk factors of severe ADRs in order to improve the benefit/risk balance of drug treatment. The ultimate goal is to develop predictive tests and models that minimize the risk of severe ADRs, and thus reduce patient suffering and health-care costs. Such tests can also be used for diagnostic purposes to differentiate an ADR from spontaneous disease.

\section{Materials and methods}

\section{Patient recruitment and data collection}

SWEDEGENE (www.swedegene.se) was established in 2008 and is a Swedish nation-wide DNA sample collection with phenotype data on cases of ADRs. Most patients are identified and recruited through the Swedish national database of spontaneously reported ADRs run by the Medical Products Agency since 1965. Non-fatal cases reported from 1990 and onwards are extracted from the database, and each reporter is asked whether the patient can be approached about participation in SWEDEGENE. In addition, patients can be recruited directly from collaborating clinicians at health-care facilities. When a clinician at these collaborating centers identifies a suitable patient, the patient is either directly recruited in collaboration with SWEDEGENE, or a research nurse at SWEDEGENE will approach the patient and ask for participation. Another mode of recruitment is through advertising campaigns.

Population controls are obtained from the Swedish TwinGene biobank that has genome-wide data from over 10000 twins as well as whole-genome sequencing data from 1000 individuals born 1958 and before [14, 15]. Only one twin out of each pair is selected as a control. Through linkage with the Swedish Prescribed Drug Register and the National Patient Register kept by the Swedish National Board of Health and Welfare, diagnoses and drug prescriptions are matched between cases and controls. We also collect treated controls with full phenotype information directly from Swedish health-care facilities when necessary. The mode of recruitment for controls is identical to that for cases.

A study kit is provided to each consenting patient or treated control including a questionnaire holding information about demographics, medical history, environmental factors and information about drug treatment, as well as an informed consent form. A research assistant contacts the patient by telephone and the questionnaire is completed through a telephone interview. If needed, copies of the participant's medical and laboratory records are obtained. In addition, blood samples are drawn at the patient's nearest health-care facility, and sent to the central laboratory at Uppsala University Hospital, where they are stored for later use. If a patient is reluctant to draw blood, saliva sampling is undertaken instead.

Phenotype data concerning the drug suspected to have caused the ADR, the indication for which the drug was prescribed, concomitant drugs and diseases, a summary code for the ADR, demographic variables (sex and age), relevant laboratory data, a brief narrative, and all information acquired through the questionnaire is compiled in a study database by a research nurse. The same questionnaire is used for all cases except for certain ADR specific questions. For treated controls, the questionnaire contains demographic variables, all drug treatments and diseases. To ensure the security of participant data, the clinical data is stored in a local encrypted database. Access to the database is limited to specific computers, and access is locked behind passwords and two-factor authentication. To further limit the potential for data breach the user is only allowed to view essential data for the user-group, with access to other parts locked behind a permission system.

Any type of genetic data is pseudonymized and stored separate from clinical data. For smaller data volumes in the range 1-20 TB, data is archived on secured encrypted drives. Data that is currently being analyzed is stored on the UPPMAX Bianca Cluster at Uppsala University (www. upmax.se). Secure archiving of larger data volumes has not yet been needed. As the genetic analyses that are conducted are not approved as clinical tests in routine health-care, genomic results are not returned to participants.

\section{Inclusion and exclusion criteria}

All patients included are at least 18 years of age and able to give informed consent. To be included in the study, the initial event should have occurred after the start of treatment and in some instances after withdrawal of the drug. Causality is assessed with the WHO standard algorithm [16]. Certain ADRs have specific inclusion and exclusion criteria and are adjudicated by clinical experts. Examples of such critera from published studies are given in Table 1.

\section{Genomic analysis}

Power calculations for GWAS using a dominant genetic model show that 50 cases and 5000 controls give us $80 \%$ 
Table 1 Examples of inclusion and exclusion criteria for cases of adverse drug reactions in published studies.

Inclusion criteria $\quad$ Exclusion criteria

Agranulocytosis $[18,19$

(1) An absolute neutrophil count of $0.5 \times 10^{9} / \mathrm{L}(\leq 500 / \mu \mathrm{L})$ or less during non-chemotherapy drug treatment or within 7 days of stopping treatment;

(2) Complete recovery after cessation of the drug, with an absolute neutrophil count of more than $1.0 \times 10^{9} / \mathrm{L}(>1000 / \mu \mathrm{L})$ or a compatible bone marrow aspirate or biopsy finding.

Angioedema due to ACEinhibitors and ARBs [41]

(1) Symptoms in the head and neck region judged to be angioedema by a physician;

(2) The initial event should occur during treatment with an ACE inhibitor or ARB;

(3) It may recur after cessation of treatment.

Atypical femoral fractures due to bisphosphonates [22]

Narcolepsy due to swine influenza A (H1N1) vaccination (Pandemrix) [21]
(1) The event should occur during or after bisphosphonate treatment;

(2) The fracture must be located along the femoral diaphysis from just distal to the lesser trochanter to just proximal to the supracondylar flare;

(3) At least four of the following features $(a-e)$ must be present:

(a) The fracture is associated with minimal or no trauma, as in a fall from a standing height or less;

(b) The fracture line originates at the lateral cortex and is substantially transverse in its orientation, although it may become oblique as it progresses medially across the femur;

(c) Complete fractures extend through both cortices and may be associated with a medial spike; incomplete fractures involve only the lateral cortex;

(d) The fracture is noncomminuted or minimally comminuted

(e) Localized periosteal or endosteal thickening of the lateral cortex is present at the fracture site ("beaking" or "flaring").

(1) Onset of symptoms after Pandemrix vaccination. Narolepsy type 1:

(1) The patient has daily periods of irrepressible need to sleep or daytime lapses into sleep occurring for at least three months:

(2) The presence of one or both of the following $(a-b)$ :

(a) Cataplexy and a mean sleep latency of $\leq 8 \mathrm{~min}$ and two or more sleep onset REM periods (SOREMPs) on a multiple sleep latency test (MSLT) performed according to standard techniques. A SOREMP (within 15 minutes of sleep onset) on the preceding nocturnal polysomnogram may replace one of the SOREMPs on the MSLT;

(b) Cerebrospinal fluid (CSF) hypocretin-1 concentration, measured by immunoreactivity, is either $\leq 110 \mathrm{pg} / \mathrm{mL}$ or $<1 / 3$ of mean values obtained in normal subjects with the same standardized assay. Narcolepsy type 2:

(1) The patient has daily periods of irrepressible need to sleep or daytime lapses into sleep occurring for at least three months;

(2) A mean sleep latency of $\leq 8 \mathrm{~min}$ and two or more SOREMPs are found on a MSLT performed according to standard techniques. A SOREMP (within 15 minutes of sleep onset) on the preceding nocturnal polysomnogram may replace one of the SOREMPs on the MSLT;

(3) Cataplexy is absent;

(4) Either CSF hypocretin-1 concentration has not been measured or CSF hypocretin-1 concentration measured by immunoreactivity is either $>110 \mathrm{pg} / \mathrm{mL}$ or $>1 / 3$ of mean values obtained in normal subjects with the same standardized assay;

(5) The hypersomnolence and/or MSLT findings are not better explained by other causes such as insufficient sleep, obstructive sleep apnea, delayed sleep phase disorder, or the effect of medication or substances or their withdrawal.
(1) Anticancer chemotherapy within 1 month of onset of agranulocytosis;

(2) Radiation therapy within the previous month;

(3) Bone marrow transplantation at any time;

(4) Ongoing infection with Epstein-Barr virus, hepatitis A virus,

HIV, cytomegalovirus, or parvovirus B19;

(5) Ongoing sepsis;

(6) Ongoing miliary tuberculosis;

(7) Current presence of chronic neutropenia (congenital cyclic or idiopathic);

(8) Ongoing immunosuppressive therapy with cytotoxic drugs;

(9) Current presence of malignant infiltration of bone marrow;

(10) Hematological diseases (eg, myelodysplasia, aplastic anemia, pancytopenia, and other blood dyscrasias, such as hemoglobin $\leq 100 \mathrm{~g} / \mathrm{L}$ or platelets $\leq 100 \times 10^{9} / \mathrm{L}$ );

(11) Current presence of systemic lupus erythematosus.

1) Symptoms coinciding with urticaria;

2) Another likely cause such as severe facial trauma or infection

3) Association with $\mathrm{C} 1$ inhibitor or complement deficiency (if this data is available);

4) Mutation in the C1 inhibitor (SERPING1) or factor XII (F12) gene (if this data is available).

1) Fractures of the femoral neck, intertrochanteric fractures with spiral subtrochanteric extension, periprosthetic fractures, and pathological fractures associated with primary or metastatic bone tumors and miscellaneous bone diseases (eg, Paget's disease, fibrous dysplasia).

1) Onset of symptoms prior to Pandemrix vaccination.

$A C E$ angiotensin-converting enzyme, $A R B$ angiotensin II receptor type 1 blocker 
power to detect an odds ratio of 3-4 with a minor allele frequency of $40 \%$, and $80 \%$ power to detect an odds ratio of 4-5 for variants with a minor allele frequency of $20 \%$. This is based on the conventional genome-wide significance threshold of $p<5 \times 10^{-8}$ [17].

\section{Results}

To date, SWEDEGENE has DNA and curated clinical data from about 2550 individuals that have experienced specific ADRs. A list of collected ADRs as per July 2019 with at least 15 cases is presented in Table 2. We have also collected 580 drug-treated controls, and the largest group is methotrexate-treated rheumatoid arthritis patients showing no signs of liver toxicity, and individuals exposed to the swine influenza A (H1N1) vaccination Pandemrix without having developed signs of narcolepsy. However, for most ADRs comparisons are made with the 5000 populations controls with genome-wide data and 1000 with wholegenome sequencing data from TwinGene.

GWAS of agranulocytosis induced by antithyroid drugs or sulfasalazine, cough induced by angiotensin-converting enzyme (ACE) inhibitors, narcolepsy induced by Pandemrix and atypical femoral fractures induced by bisphosphonates have been published [18-22]. SWEDEGENE has also provided cases and controls in several other collaborative studies, such as GWAS and whole exome sequencing of statin
Table 2 Collected adverse drug reaction diagnoses with at least 15 cases presented in decreasing order of frequency as per July, 2019.

\begin{tabular}{|c|c|c|}
\hline ADR diagnosis & Main suspected drug classes & $n$ \\
\hline Angioedema & $\begin{array}{l}\text { ACE-inhibitors, angiotensin receptor blockers, } \\
\text { immunosuppressants, NSAIDs, antibiotics }\end{array}$ & 514 \\
\hline Liver toxicity & $\begin{array}{l}\text { Antibiotics, immunosuppressants, NSAIDs, lipid lowering } \\
\text { drugs, antiarrhythmics, antiepileptics, antidepressants, } \\
\text { herbals, antithyroid drugs, alcohol abuse drugs, } \\
\text { anticoagulants }\end{array}$ & 461 \\
\hline $\begin{array}{l}\text { Cytopenias (agranulocytosis, } \\
\text { thrombocytopenia and anemia) }\end{array}$ & $\begin{array}{l}\text { Antithyroid drugs, sulfasalazine, NSAIDs, antibiotics, } \\
\text { immunosuppressants }\end{array}$ & 270 \\
\hline Cough & ACE-inhibitors & 152 \\
\hline Urticaria & $\begin{array}{l}\text { Antibiotics, immunosuppressants, contrast media, NSAIDs, } \\
\text { antiepileptics }\end{array}$ & 152 \\
\hline $\begin{array}{l}\text { Alanine aminotransferase (ALT) } \\
\text { elevation in rheumatoid arthritis } \\
\text { patients }\end{array}$ & Methotrexate & 130 \\
\hline Anaphylaxis & Immunosuppressants, NSAIDs, antibiotics, iron & 112 \\
\hline Central nervous system toxicity & Antibiotics, antimalarial drugs, antiviral drugs, interferon & 94 \\
\hline Narcolepsy & H1N1 vaccine (Pandemrix) & 83 \\
\hline Pancreatitis & $\begin{array}{l}\text { Immunosuppressants, ACE-inhibitors, lipid lowering drugs, } \\
\text { chemotherapy, antidiabetics }\end{array}$ & 82 \\
\hline Renal toxicity & $\begin{array}{l}\text { NSAIDs, antibiotics, immunosuppressants, antidiabetics, } \\
\text { antiviral drugs, anticoagulants }\end{array}$ & 70 \\
\hline $\begin{array}{l}\text { Stevens-Johnson syndrome/toxic } \\
\text { epidermal necrolysis }\end{array}$ & Antiepileptics, antibiotics, immunosuppressants, allopurinol & 63 \\
\hline Osteonecrosis & Bisphosphonates & 61 \\
\hline Atypical fracture & Bisphosphonates & 58 \\
\hline Bleeding & Non-vitamin $\mathrm{K}$ oral anticoagulants (NOAC) & 52 \\
\hline Myopathy/Rhabdomyolysis & Lipid lowering drugs & 51 \\
\hline Other allergic reactions & $\begin{array}{l}\text { Antibiotics, immunosuppressants, NSAIDs, antiepileptics, } \\
\text { proton pump inhibitors }\end{array}$ & 51 \\
\hline Phototoxicity & NSAIDs, antibiotics & 50 \\
\hline Metabolic disorder/weight gain & Antidepressants, neuroleptics & 46 \\
\hline Hyponatraemia & Antidepressants, antiepileptics & 35 \\
\hline Hair loss & $\begin{array}{l}\text { Immunosuppressants, anticoagulants, antiepileptics, lipid } \\
\text { lowering drugs, ACE-inhibitors }\end{array}$ & 28 \\
\hline Tendon rupture & Fluoroquinolones & 25 \\
\hline Torsade de Pointes/QT-prolongation & Beta blockers, antidepressants, antiarrhythmics, antibiotics & 22 \\
\hline
\end{tabular}

In addition to the below numbers, a total of 580 drug-treated controls have been recruited 
induced myopathy [23, 24], drug induced liver toxicity [25-30], and hypersensitivity reactions to carbamazepine [31]. Additional GWAS and whole genome exome sequencing studies on ADR diagnoses collected by SWEDEGENE are currently underway. In addition, 1000 selected SWEDEGENE individuals have been whole genome sequenced and are being compared with 1000 whole genome sequenced individuals from TwinGene. This will give us the possibility to find novel genetic associations with ADRs and to map population frequencies of known pharmacogenomic targets in the Swedish population. As for planned analyses, enrichment tests [32], pathway based analysis, and genome-wide complex trait analysis [33] will be performed beyond GWAS.

As many pharmacogenomic targets are rare variants, novel associations in a limited sample population can be hard to detect. To increase the probability there are two options; increase the sample size or decrease the number of tested associations. As rare ADRs are, by definition, rare, our option is to decrease the number of tests. This will be done by selecting variants a priori based on predicted mutation effects using software and databases as Ensembl Variant Effect Predictor (VEP) [34], Eigen- [35] or Combined Annotation-Dependent Depletion (CADD) scores [36]. To further decrease the number of tests we will use enrichment tests such as burden and non-burden tests, to test for genetic burden on an exon or pathway basis [32].

\section{Future perspective}

SWEDEGENE is an important resource for pharmacogenetic studies of ADRs. Due to our unique nation-wide collection, SWEDEGENE has the potential to discover novel genetic and clinical risk factors for rare and serious ADRs, with the ultimate goal to identify patients at risk and to improve the benefit/risk balance of drug treatment. Since pharmacogenetic variants in general have larger effect sizes than variants that increase the risk of complex diseases [37], the clinical benefit is estimated to be great. It is also easier to select an alternative drug than to modify risk factors for complex diseases. It has already been shown that hospitalizations and emergency department visits can be reduced by genotyping elderly polypharmacy patients [38], and that pre-prescription genotyping is cost-effective for certain ADRs [39]. Barriers for implementing genotype-based drug therapy will be overcome once patients have their genome readily available in the medical record [40]. This is estimated to happen within the near future through emerging Precision Medicine initiatives. SWEDEGENE is well placed to discover novel gene-ADR associations to be analyzed in these initiatives and invites collaborators for joint efforts.

Acknowledgements Niclas Eriksson at Uppsala Clinical research Center-UCR, Uppsala, Sweden, is acknowledged for statistical expertize, and Sofia Attelind, Maria Larsson and Anders Sundström at the Medical Products Agency, Uppsala, Sweden, for arranging regular searches of diagnoses of interest in the Swedish national database of spontaneously reported ADRs. The SNP\&SEQ Technology Platform at Uppsala University, which is part of the National Genomics Infrastructure, is acknowleded for genotyping and sequencing. We acknowledge The Swedish Twin Registry for access to data. The Swedish Twin Registry is managed by Karolinska Institutet. We gratefully acknowledge Björn Beermann, Ingemar Persson and Gunilla Sjölin-Forsberg and their early support for the project at the Swedish Medical Products Agency. We further greatfully acknowledge the work of the Swedegene team: Ulrica Ramqvist, Charlotta Haglund, Sofie Collin, Eva Prado Lopez, and Hugo Kohnke (Department of Medical Sciences, Clinical Pharmacology, Uppsala University, Uppsala, Sweden).

Funding This research is supported by the Swedish Research Council (Medicine 521-2011-2440, 521-2014-3370 and 2018-03307), Swedish Heart-Lung Foundation (20120557, 20140291 and 20170711), the Medical Products Agency, Science for Life Laboratory Swedish Genomes Program (NP00085), Selander's Foundation, Thureus' Foundation, and Clinical Research Support (Avtal om Läkarutbildning och Forskning) at Uppsala University Hospital. Erik Eliasson was supported by a Stockholm County Council research grant ALF20190536. The SNP\&SEQ Technology Platform is supported by the Swedish Research Council for Infrastructures, Science for Life Laboratory, and the Knut and Alice Wallenberg Foundation. Computations are performed on resources provided by the Swedish National Infrastructure for Computing through the Uppsala Multidisciplinary Center for Advanced Computational Science (UPPMAX). The Swedish Twin Registry receives funding through the Swedish Research Council under the grant no 2017-00641.

\section{Compliance with ethical standards}

Conflict of interest The authors declare that they have no conflict of interest.

Ethical approval SWEDEGENE is approved by the regional ethics committee in Uppsala, Sweden: EPN 2008/213 and 2010/231.

Publisher's note Springer Nature remains neutral with regard to jurisdictional claims in published maps and institutional affiliations.

Open Access This article is licensed under a Creative Commons Attribution 4.0 International License, which permits use, sharing, adaptation, distribution and reproduction in any medium or format, as long as you give appropriate credit to the original author(s) and the source, provide a link to the Creative Commons license, and indicate if changes were made. The images or other third party material in this article are included in the article's Creative Commons license, unless indicated otherwise in a credit line to the material. If material is not included in the article's Creative Commons license and your intended use is not permitted by statutory regulation or exceeds the permitted use, you will need to obtain permission directly from the copyright holder. To view a copy of this license, visit http://creativecommons. org/licenses/by/4.0/.

\section{References}

1. Odar-Cederlof I, Oskarsson P, Ohlen G, Tesfa Y, Bergendal A, Hellden A, et al. [Adverse drug effect as cause of hospital 
admission. Common drugs are the major part according to the cross-sectional study]. Lakartidningen. 2008;105:890-3.

2. von Euler M, Eliasson E, Ohlen G, Bergman U. Adverse drug reactions causing hospitalization can be monitored from computerized medical records and thereby indicate the quality of drug utilization. Pharmacoepidemiology drug Saf. 2006;15:179-84.

3. Lundkvist J, Jonsson B. Pharmacoeconomics of adverse drug reactions. Fundam Clin Pharm. 2004;18:275-80.

4. Fryckstedt J, Asker-Hagelberg C. [Drug-related problems common in the emergency department of internal medicine. The cause of admission in almost every third patient according to quality follow-up]. Lakartidningen. 2008;105:894-8.

5. Wester K, Jonsson AK, Spigset O, Druid H, Hagg S. Incidence of fatal adverse drug reactions: a population based study. Br J Clin Pharm. 2008;65:573-9.

6. Gyllensten H, Hakkarainen KM, Hagg S, Carlsten A, Petzold M, Rehnberg C, et al. Economic impact of adverse drug events-a retrospective population-based cohort study of 4970 adults. PLoS ONE 2014;9:e92061.

7. Carr DF, Pirmohamed M. Biomarkers of adverse drug reactions. Exp Biol Med (Maywood). 2018;243:291-9.

8. Liu YP, Xu HQ, Li M, Yang X, Yu S, Fu WL, et al. Association between thiopurine S-methyltransferase polymorphisms and azathioprine-induced adverse drug reactions in patients with autoimmune diseases: a meta-analysis. PLoS ONE 2015;10: e0144234.

9. Meyboom RH, Egberts AC, Edwards IR, Hekster YA, de Koning FH, Gribnau FW. Principles of signal detection in pharmacovigilance. Drug Saf. 1997;16:355-65.

10. Yip VL, Hawcutt DB, Pirmohamed M. Pharmacogenetic markers of drug efficacy and toxicity. Clin Pharmacol therapeutics. 2015;98:61-70.

11. Hetherington S, Hughes AR, Mosteller M, Shortino D, Baker KL, Spreen W, et al. Genetic variations in HLA-B region and hypersensitivity reactions to abacavir. Lancet. 2002;359:1121-2.

12. Hetherington S, McGuirk S, Powell G, Cutrell A, Naderer O, Spreen B, et al. Hypersensitivity reactions during therapy with the nucleoside reverse transcriptase inhibitor abacavir. Clin therapeutics. 2001;23:1603-14.

13. Rauch A, Nolan D, Martin A, McKinnon E, Almeida C, Mallal S. Prospective genetic screening decreases the incidence of abacavir hypersensitivity reactions in the Western Australian HIV cohort study. Clin Infect Dis. 2006;43:99-102.

14. Magnusson PK, Almqvist C, Rahman I, Ganna A, Viktorin A, Walum H, et al. The Swedish Twin Registry: establishment of a biobank and other recent developments. Twin Res Hum Genet. 2013;16:317-29.

15. Ameur A, Dahlberg J, Olason P, Vezzi F, Karlsson R, Martin M, et al. SweGen: a whole-genome data resource of genetic variability in a cross-section of the Swedish population. Eur J Hum Genet. 2017;25:1253-60.

16. The Uppsala Monitoring Centre. The use of the WHO-UMC system for standardised case causality assessment. https://www. who.int/medicines/areas/quality_safety/safety_efficacy/WHOca usality_assessment.pdf. Accessed 12 Jan 2020.

17. Sham PC, Purcell SM. Statistical power and significance testing in large-scale genetic studies. Nat Rev Genet. 2014;15:335-46.

18. Hallberg P, Eriksson N, Ibanez L, Bondon-Guitton E, Kreutz R, Carvajal A, et al. Genetic variants associated with antithyroid drug-induced agranulocytosis: a genome-wide association study in a European population. Lancet Diabetes Endocrinol. 2016;4:507-16.

19. Wadelius M, Eriksson N, Kreutz R, Bondon-Guitton E, Ibanez L, Carvajal A, et al. Sulfasalazine-induced agranulocytosis is associated with the human leukocyte antigen locus. Clin Pharm Ther. 2017;103:843-53.
20. Hallberg P, Persson M, Axelsson T, Cavalli M, Norling P, Johansson HE, et al. Genetic variants associated with angiotensinconverting enzyme inhibitor-induced cough: a genome-wide association study in a Swedish population. Pharmacogenomics. 2017;18:201-13.

21. Hallberg P, Smedje H, Eriksson N, Kohnke H, Daniilidou M, Ohman I, et al. Pandemrix-induced narcolepsy is associated with genes related to immunity and neuronal survival. EBioMedicine. 2019;40:595-604.

22. Kharazmi M, Michaelsson K, Schilcher J, Eriksson N, Melhus H, Wadelius $\mathrm{M}$, et al. A genome-wide association study of bisphosphonate-associated atypical femoral fracture. Calcif Tissue Int. 2019;105:51-67.

23. K Siddiqui M, Maroteau C, Veluchamy A, Tornio A, Tavendale $\mathrm{R}$, Carr F, et al. A common missense variant of LILRB5 is associated with statin intolerance and myalgia. Eur Heart J. 2017;38:3569-75.

24. Floyd JS, Bloch KM, Brody JA, Maroteau C, Siddiqui MK, Gregory R, et al. Pharmacogenomics of statin-related myopathy: meta-analysis of rare variants from whole-exome sequencing. PLoS ONE 2019;14:e218115.

25. Nicoletti P, Aithal GP, Bjornsson ES, Andrade RJ, Sawle A, Arrese M, et al. Association of liver injury from specific drugs, or groups of drugs, with polymorphisms in HLA and other genes in a genome-wide association Study. Gastroenterology. 2017; 152:1078-89.

26. Urban TJ, Shen Y, Stolz A, Chalasani N, Fontana RJ, Rochon J, et al. Limited contribution of common genetic variants to risk for liver injury due to a variety of drugs. Pharmacogenet Genomics. 2012;22:784-95.

27. Kowalec K, Wright GEB, Drogemoller BI, Aminkeng F, Bhavsar AP, Kingwell E, et al. Common variation near IRF6 is associated with IFN-beta-induced liver injury in multiple sclerosis. Nat Genet. 2018;50:1081-5.

28. Cirulli ET, Nicoletti P, Abramson K, Andrade RJ, Bjornsson ES, Chalasani N, et al. A missense variant in PTPN22 is a risk factor for drug-induced liver injury. Gastroenterology. 2019;156: 1707-16. e1702.

29. Nicoletti P, Aithal GP, Chamberlain TC, Coulthard S, Alshabeeb $\mathrm{M}$, Grove JI, et al. Drug-Induced liver injury due to flucloxacillin: relevance of multiple human leukocyte antigen alleles. Clin Pharm Ther. 2019;106:245-53.

30. Nicoletti P, Werk AN, Sawle A, Shen Y, Urban TJ, Coulthard SA, et al. HLA-DRB1*16: 01-DQB1*05: 02 is a novel genetic risk factor for flupirtine-induced liver injury. Pharmacogenet Genomics. 2016;26:218-24.

31. Nicoletti P, Barrett S, McEvoy L, Daly AK, Aithal G, Lucena MI, et al. Shared Genetic risk factors across carbamazepine-induced hypersensitivity reactions. Clin Pharm Ther. 2019;106:1028-36.

32. Lee S, Emond MJ, Bamshad MJ, Barnes KC, Rieder MJ, Nickerson DA, et al. Optimal unified approach for rare-variant association testing with application to small-sample case-control whole-exome sequencing studies. Am J Hum Genet. 2012;91:224-37.

33. Yang J, Lee SH, Goddard ME, Visscher PM. GCTA: a tool for genome-wide complex trait analysis. Am J Hum Genet. 2011;88:76-82.

34. McLaren W, Gil L, Hunt SE, Riat HS, Ritchie GR, Thormann A, et al. The Ensembl Variant Effect Predictor. Genome Biol. 2016;17:122.

35. Ionita-Laza I, McCallum K, Xu B, Buxbaum JD. A spectral approach integrating functional genomic annotations for coding and noncoding variants. Nat Genet. 2016;48:214-20.

36. Rentzsch P, Witten D, Cooper GM, Shendure J, Kircher M. CADD: predicting the deleteriousness of variants throughout the human genome. Nucleic Acids Res. 2019;47:D886-94. 
37. Maranville JC, Cox NJ. Pharmacogenomic variants have larger effect sizes than genetic variants associated with other dichotomous complex traits. Pharmacogenomics J. 2016;16:388-92.

38. Elliott LS, Henderson JC, Neradilek MB, Moyer NA, Ashcraft $\mathrm{KC}$, Thirumaran RK. Clinical impact of pharmacogenetic profiling with a clinical decision support tool in polypharmacy home health patients: a prospective pilot randomized controlled trial. PLoS ONE 2017;12:e170905.
39. Collins SL, Carr DF, Pirmohamed M. Advances in the pharmacogenomics of adverse drug reactions. Drug Saf. 2016;39:15-27.

40. Relling MV, Evans WE. Pharmacogenomics in the clinic. Nature. 2015;526:343-50.

41. Wadelius M, Marshall SE, Islander G, Nordang L, Karawajczyk M, Yue QY, et al. Phenotype standardization of angioedema in the head and neck region caused by agents acting on the angiotensin system. Clin Pharmacol therapeutics. 2014;96:477-81. 